$\overline{\text { Report }}$

\title{
Investigation of Residual DNAs in Sugar from Sugar Beet (Beta vulgaris L.)
}

(Received August 5, 2008)

\author{
Taichi Oguchi ${ }^{1, \ddagger}$, Mari Onishi ${ }^{2}$, Yukie Chikagawa ${ }^{2}$, Takashi Kodama ${ }^{3}$, Emiri Suzuki ${ }^{1}$, \\ Masaki Kasahara ${ }^{1,3}$, Hiroshi Akiy ama ${ }^{4}$, Reiko Teshima ${ }^{4}$, Satoshi Futo ${ }^{2}$, \\ Akihiro Hino ${ }^{1}$, Satoshi Furui ${ }^{1, *}$ and Kazumi Kitta ${ }^{1}$ \\ ${ }^{1}$ National Agriculture and Food Research Organization, National Food Research Institute: \\ 2-1-12 Kannondai, Tsukuba, Ibaraki 305-8642, Japan; \\ ${ }^{2}$ Fasmac Co., Ltd.: 5-1-3 Midorigaoka, Atsugi, Kanagawa 243-0041, Japan; \\ ${ }^{3}$ Food and Agricultural Materials Inspection Center: 2-1 Shintoshin, \\ Chuo-ku, Saitama, Saitama 330-9731, Japan; \\ ${ }^{4}$ National Institute of Health Sciences: 1-18-1 Kamiyoga, Setagaya-ku, \\ Tokyo 158-8501, Japan; *Corresponding author
}

\begin{abstract}
Genetically modified (GM) sugar beets have been bred for use as food and animal feed. To evaluate the applicability of GMO analyses to beet sugar products, we investigated residual DNA in eight sorts of in-process beet sugar samples and commercial beet sugar products. Polymerase chain reaction (PCR) analyses with taxon-specific primers indicated that sugar beet DNA was degraded at an early stage of sugar processing, and no PCR amplification was detected from the investigated sugar products because of low DNA recovery and/or PCR inhibition.
\end{abstract}

Key words: genetically modified (GM); sugar beet (Beta vulgaris L.); deoxyribonucleic acid (DNA); polymerase chain reaction (PCR); taxon specific DNA

\section{Introduction}

Recombinant DNA technologies have been increasingly used in modern farming and are thought to offer various advantages. The global area of genetically modified (GM) crops exceeded 120 million hectares in 2007 , and is expected to continue to rise ${ }^{1}$. GM crops have been authorized for use as food and/or animal feed in many countries based on their own criteria for safety assessment. However, consumers have demanded appropriate information and labeling for foods derived from GM crops. Thus, labeling systems have been introduced for GM foods in the European Union (EU), Korea, Japan, Australia and other countries, and these systems are distinct from each other ${ }^{2}$. In addition, many countries have been seeking ways for the coexistence of cultivation of conventional crops and GM crops. In these situations, scientifically sound GMO detection methods have become more important. Sugar beet is a major agricultural crop, used as the raw material for refined sugar, especially in cool regions. GM sugar beets have also been bred and authorized for food and/or feed applications by many countries. Therefore it is desirable to survey the commercial distribution of GM sugar beets and/or their processed foods. However, it has not

$\ddagger$ Present address: National Institute of Agribiological Sciences: 2-1-2 Kannondai, Tsukuba, Ibaraki 305-8602, Japan been established whether or not sufficient amounts and/or quality of DNAs for DNA extraction-based analyses remain in refined beet sugar products. In this study, we investigated residual DNA in commercial beet sugar products and assessed the appropriateness of GMO analysis methods for processed sugar beet products for regulatory purposes.

\section{Materials and Methods}

\section{Materials}

Fresh sugar beet and eight sorts of in-process samples of sugar beets were kindly provided by the Japan Beet Sugar Association. The sampling points of the inprocess samples are indicated in Fig. 1. Eight sorts of commercial beet sugar samples were purchased from markets in Tokyo and Sapporo in Japan. Nineteen varieties of sugar beets and four plants closely related to sugar beets were provided by the National Agricultural Research Center for the Hokkaido Region, and used for the specificity tests of PCR primers.

\section{DNA extraction}

For the PCR experimental controls, DNAs were extracted from leaves or aerial parts of seedlings with a DNeasy ${ }^{\circledR}$ plant Maxi kit (QIAGEN, Hilden, Germany) according to the attached protocol. DNA extraction from in-process samples and beet sugar products was performed using an anion exchange column, Genomic-tip 20/G (QIAGEN), and the experimental pro- 

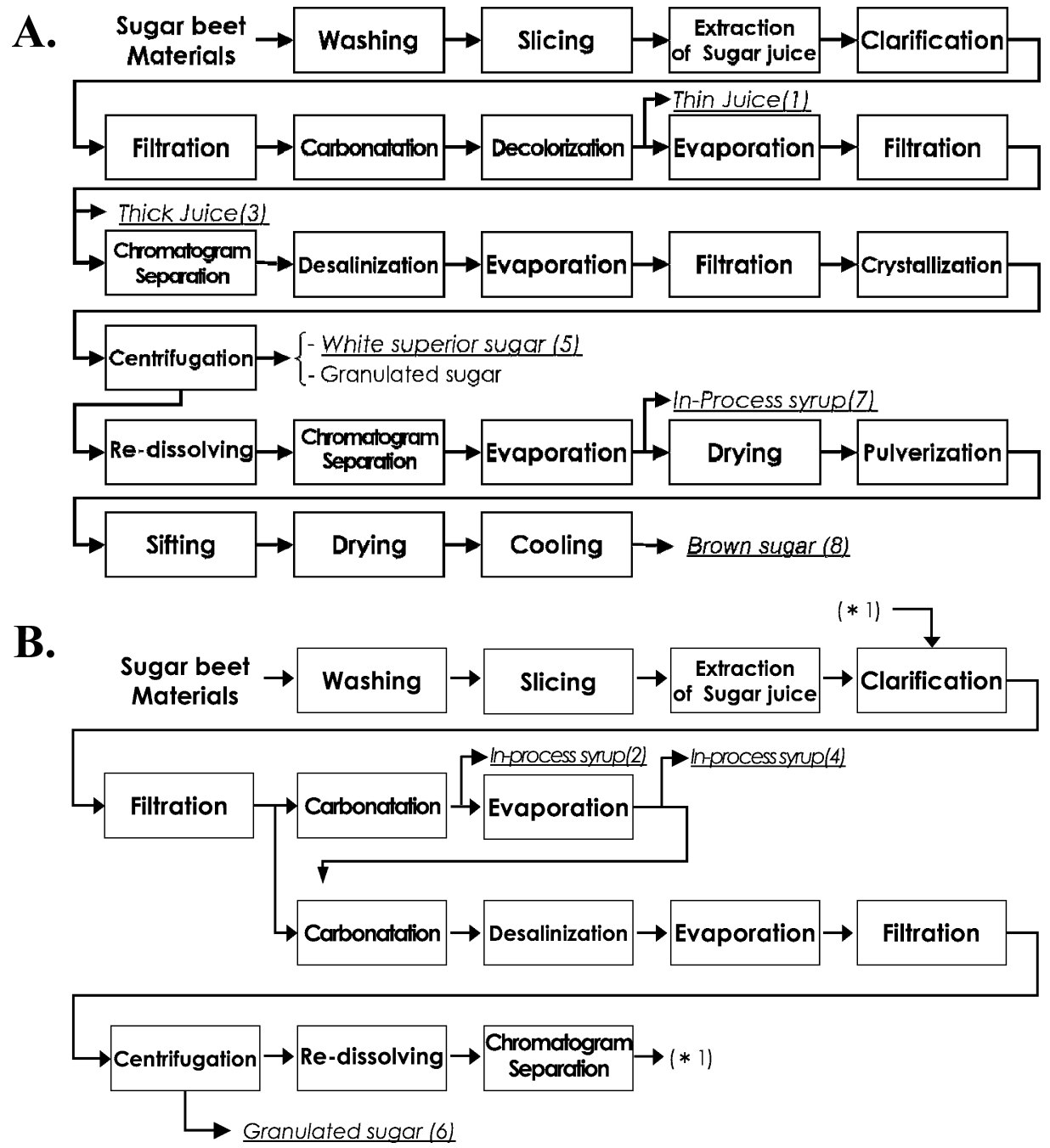

Fig. 1. Flow charts of beet sugar processes

Sugar beet materials are washed and sliced into thin strips called cassettes, which go through a diffuser machine to extract raw sugar juices. The raw juices are clarified and filtered to remove beet pulp. Filtered raw juices are mixed with "milk of lime", which consists of calcium oxide and carbon dioxide gas, and non-sugar components in the juices are precipitated with the calcium carbonate. Then, the supernatant is called thin juice. The thin juice is purified and evaporated to obtain thicker juice. The thick juice goes into a crystallizer tank and fine sugar crystals grow. The crystallized sugar is purified to fine sugar products, such as white superior sugar and granulated sugar. Much sugar remains in the syrup, and then chromatographic separation is performed on the syrup to produce brown sugar. The processes shown here are two examples (flow chart A and B) and there are some differences in processing from company to company. The underlined terms indicated the points at which specimens of the in-process products were taken for use in this study, and the numbers in parentheses correspond to the numbers in Table 1 and Fig. 4.

cedure generally followed the Japanese standard method for GMO analysis on food items with some modifications ${ }^{3)} * 1$. Extracted DNAs were finally resuspended in $40 \mu \mathrm{L}$ of sterile distilled water. All extraction experiments were performed in a clean laboratory with designated operators, and two independent extracts were made from the in-process samples and beet sugar products.

*1 Notification No. 110 (Mar. 27, 2001), Department of Food Safety, MHLW, Japan (2001).
Estimation of amount and quality of extracted DNAs

The amount and quality of the extracted DNA solutions was estimated from the ultraviolet (UV) absorption spectrum measured by a UV spectrophotometer, ND-1000 (NanoDrop ${ }^{\circledR}$ Technologies, Wilmington, DE, USA). $1.5 \mu \mathrm{L}$ of each undiluted DNA extract was directly subjected to UV measurement, and the UV absorptions at $230 \mathrm{~nm}, 260 \mathrm{~nm}$, and $280 \mathrm{~nm}$ were observed. In addition, as the experimental control, we also performed DNA quantitation using the Qant-iT ${ }^{\mathrm{TM}}$ PicoGreen ${ }^{\circledR}$ dsDNA quantitation reagent (Molecular Probes, Eugene, OR, USA) and Cytofluore ${ }^{\circledR} 2350$ (Millipore, Billerica, MA, USA). The experimental proce- 
Table 1. Quality of the extracted DNA from in-process samples and beet sugar produsts

\begin{tabular}{|c|c|c|c|c|c|c|}
\hline$\#$ & Type & Sample ${ }^{a}$ & $260 \mathrm{~nm} / 280 \mathrm{~nm}^{\mathrm{b}}$ & $260 \mathrm{~nm} / 230 \mathrm{~nm}^{\mathrm{c}}$ & $\begin{array}{l}\text { Conc. } \\
(\mathrm{ng} / \mu \mathrm{L})^{\mathrm{d}}\end{array}$ & $\begin{array}{l}\text { Conc. } \\
(\mathrm{ng} / \mu \mathrm{L})^{\mathrm{e}}\end{array}$ \\
\hline 1 & In-process samples & Thin juice & 2.0 & 0.28 & 13.4 & 8.36 \\
\hline 2 & & In-process syrup & 1.2 & 0.08 & 3.3 & 0.72 \\
\hline 3 & & Thick juice & 2.3 & 0.07 & 3.0 & 0.58 \\
\hline 4 & & In-process syrup & 1.7 & 0.09 & 3.8 & 0.83 \\
\hline 5 & & White superior sugar & 1.2 & 0.08 & 2.2 & 0.36 \\
\hline 6 & & Granulated sugar & 1.7 & 0.09 & 3.0 & -0.16 \\
\hline 7 & & In-process syrup & 1.7 & 0.07 & 3.1 & -0.03 \\
\hline 8 & & Brown Sugar & 1.3 & 0.10 & 4.3 & 0.01 \\
\hline 9 & Commercial beet & Brown sugar (1) & 2.8 & 0.09 & 4.3 & 0.39 \\
\hline 10 & sugar products & Brown sugar (2) & 4.0 & 0.08 & 3.7 & 0.85 \\
\hline 11 & & Syrup-type product added oligosaccharide & 2.3 & 0.06 & 2.3 & 0.70 \\
\hline 12 & & Granulated sugar (1) & 2.7 & 0.06 & 2.9 & 0.72 \\
\hline 13 & & White superior sugar & 20.3 & 0.07 & 2.7 & 0.73 \\
\hline 14 & & Brown sugar $(3)$ & 2.2 & 0.06 & 2.3 & 0.73 \\
\hline 15 & & Bleached brown sugar & 1.2 & 0.07 & 3.5 & 0.68 \\
\hline 16 & & Granulated sugar (2) & 5.0 & 0.06 & 2.6 & 0.66 \\
\hline
\end{tabular}

${ }^{a}$ DNA extractions were performed with two independent replications, and UV absorptions are given as the means of them.

b The ratios of DNA solution in good condition usually range from 1.7 to 2.0.

c The ratios of DNA solution in good condition are usually more than 0.6.

d Calculated concentrations estimated from UV absorptions.

${ }^{\mathrm{e}}$ Calculated concentrations estimated using the Qant-iT ${ }^{\mathrm{TM}}$ PicoGreen ${ }^{\circledR}$ reagent.

dures followed the manufacturers' protocols.

\section{Qualitative PCR analysis}

The GeneAmp ${ }^{\circledR}$ PCR system 9700 (Applied Biosystems; ABI, Foster City, CA, USA) was used in the max mode, and the PCR mixture, in a final volume of 25 $\mu \mathrm{L}$, consisted of $1 \mathrm{X}$ PCR buffer II (ABI), $0.2 \mathrm{mM}$ dNTPs (ABI), $1.5 \mathrm{mM} \mathrm{MgCl}_{2}$ (ABI), $0.025 \mathrm{U}$ AmpliTaq ${ }^{\circledR}$ Gold DNA polymerase (ABI), $0.5 \mu \mathrm{M}$ each primer and DNA sample. Twenty-five ng $(2.5 \mu \mathrm{L}$ of $10 \mathrm{ng} / \mu \mathrm{L})$ of template DNA, as calculated from the UV absorption at 260 $\mathrm{nm}$, was used for PCR analysis unless otherwise described. When the concentration of extracted DNA was not enough, the maximum volume $(17,875 \mu \mathrm{L})$ of undiluted DNA extract was used for the reaction. The primer pairs used in this study were as follows: primer pair $1 ; 5^{\prime}$-GCCCCCAAAAACCCTTCA-3' and 5'-GGGCAATTTGGTAGGCTTCTT-3', and primer pair $2 ; 5^{\prime}$ ATCCCTGCAGCCATCAGTGA- $3^{\prime}$ and $5^{\prime}$-ACCAGTAAGCCACTCAACAGTCAA-3'. As an inhibition assay of PCR, we observed amplification from each reaction mixture spiked with 260 pg of extracted DNA from the sugar beet plant (cv. Skane). Twenty-five $\mu \mathrm{L}$ of PCR mixture consisted of $1 \mathrm{X}$ PCR buffer II (ABI), $0.2 \mathrm{mM}$ dNTPs (ABI), $1.5 \mathrm{mM} \mathrm{MgCl}_{2}$ (ABI), $0.025 \mathrm{U}_{\text {AmpliTaq }}{ }^{\circledR}$ Gold DNA polymerase (ABI), $0.5 \mu \mathrm{M}$ each primer, 16,875 $\mu \mathrm{L}$ of DNA extraction, and $1 \mu \mathrm{L}$ of $260 \mathrm{pg} / \mu \mathrm{L}$ spike DNA.

The qualitative PCR reactions was performed on a thermal cycler, the Silver 96-Well GeneAmp ${ }^{\circledR}$ PCR System 9700 (ABI) in Max mode, according to the following step-cycle program: pre-incubation at $95^{\circ} \mathrm{C}$ for $10 \mathrm{~min}$; 40 cycles consisting of denaturation at $95^{\circ} \mathrm{C}$ for $0.5 \mathrm{~min}$, annealing at $60^{\circ} \mathrm{C}$ for $0.5 \mathrm{~min}$ and extension at $72^{\circ} \mathrm{C}$ for 0.5 min; followed by a final extension at $72^{\circ} \mathrm{C}$ for 7 min. After the amplification, PCR products were electrophoresed on 3\% agarose gels buffered with TrisAcetate-EDTA (TAE) solution.

\section{Results and Discussion}

Yield and quality of extracted DNA from in-process samples and beet sugar products

DNA was extracted from $1 \mathrm{~g}$ of each in-process or beet sugar product sample with the anion exchange column, Genomic-tip 20/G (QIAGEN), which we have been using for the DNA extraction of highly processed foods ${ }^{3)}$. The yield and quality of the extracted DNA solution was estimated from the UV absorption spectrum. The UV absorption ratios at $260 \mathrm{~nm} / 280 \mathrm{~nm}$ of most samples were out of the optimal range of 1.7 to 2.0, which indicated poor quality of DNA (Table 1). Moreover, absorption ratios of $260 \mathrm{~nm} / 230 \mathrm{~nm}$ ranged from 0.06 to 0.28 , which implied that sugars contaminated the extracted DNA solutions (Table 1). Based on the UV absorption at $260 \mathrm{~nm}$, the calculated concentrations of extracted DNAs ranged from $2.2 \mathrm{ng} / \mu \mathrm{L}$ (white superior sugar) to $13.4 \mathrm{ng} / \mu \mathrm{L}$ (thin juice) and from $2.3 \mathrm{ng} / \mu \mathrm{L}$ (syrup-type product with added oligosaccharide, and brown sugar \#3) to $4.3 \mathrm{ng} / \mu \mathrm{L}$ (brown sugar \#1) for in-process samples and commercial products, respectively (Table 1). Following the Japanese standard method for GM analyses, we generally used $25 \mathrm{ng}$ of DNA, i.e., $2.5 \mu \mathrm{L}$ of $10 \mathrm{ng} / \mu \mathrm{L}$ diluted DNA, for quantitative PCR analysis. Thus, these yields were very low. In addition, the UV absorption measurements indicated that contamination with nucleic acids and/or other substances unrelated to PCR amplification was probably presnt. In fact, fluorometric quantitation of double- 

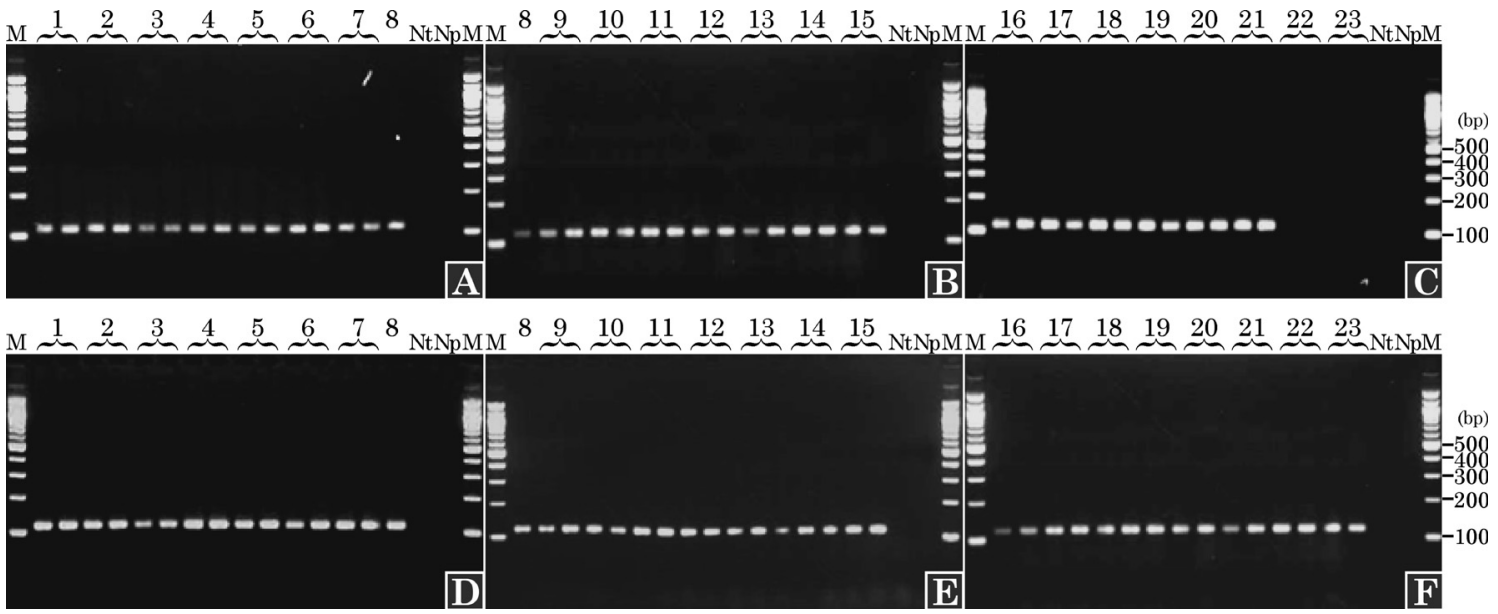

Fig. 2. Specificities of primer pairs used in this study

PCR products amplified with primer pair $1(\mathrm{~A}-\mathrm{C})$ and primer pair $2(\mathrm{D}-\mathrm{F})$ were electrophoresed on $3 \%$ agarose gels. Lanes 1-19, the amplification of sugar beet (Beta vulgaris L. subsp. vulgaris) DNA extracted from seedlings of cultivar Monomidori, Monohikari, Monoperl, Monowhite, Monohomare, Mighty, Schwerdt, Kabutomaru, Yukihinode, Kitamasari, Etopirika, Nozomi, Skane, Freuden, NK-150, C-110, Amano, Hinderupgaad, and Detroit Dark Red, respectively; lanes 20 and 21, the amplification of chard plant (Beta vulgaris L. subsp. vulgaris var. cicla) DNA extracted from seedlings of line FK-02-09 and FK-02-34, respectively; lane 22, the amplification of chenopodium plant (Chenopodium amaranticolor) DNA extracted from seedlings; lane 23, the amplification of quinua plant (C. quinoa) DNA extracted from seedlings; Nt, negative control without template; Np, negative control without primers; M, 100 bp ladder size standard. The predicted sizes of the specific amplification products with primer pair 1 and primer pair 2 are $116 \mathrm{bp}$ and $121 \mathrm{bp}$, respectively.

stranded (ds) DNA using the Qant-iT ${ }^{\mathrm{TM}}$ PicoGreen ${ }^{\circledR}$ dsDNA quantitation reagent gave concentrations of extracted DNAs ranging up to $8.36 \mathrm{ng} / \mu \mathrm{L}$ (thin juice), and up to $0.85 \mathrm{ng} / \mu \mathrm{L}$ (brown sugar \#2) for in-process samples and commercial products, respectively (Table 1). These results suggested that it was difficult to extract sufficient amounts of DNA at suitable concentrations for PCR analysis from the final products of sugar beets.

Development of sugar beet-specific qualitative PCR method

To detect residual DNA with high sensitivity, we tried to amplify and to sugar beet-specific DNA fragments from the extracted DNAs of the in-process products and the beet sugar products. For this purpose, we designed two pairs of taxon-specific primers, which were elaborated to detect single nucleotide polymorphism (SNP) markers ${ }^{4}$. These primer pairs were specifically able to detect the 19 cultivars of sugar beet investigated in this study (Fig. 2). Amplification was also observed in some reactions with other plants that are closely related with sugar beet, such as chard (Beta vulgaris L. subsp. vulgaris var. cicla), chenopodium (Chenopodium amaranticolor), and quinua (C. quinoa). No amplification was observed in reactions with DNAs from other plants, i.e., soy, maize, rice, wheat, cotton, oilseed, alfalfa, potato and barley (data not shown). The detection limit of these primer pairs was 5 copies of genomic DNA, calculated from the UV absorption using a $C$-value of $26 \mathrm{pg} / 2 C^{5)}$ (Fig. 3). Therefore, we concluded that these primer pairs were suitable for use in the following experiments. Moreover, these primer

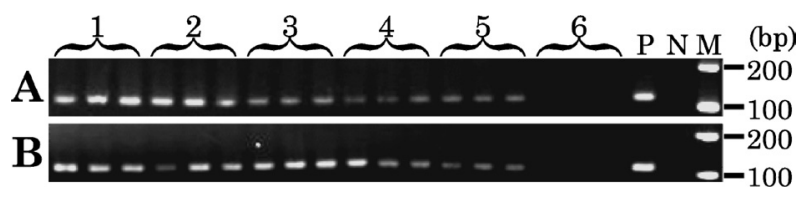

Fig. 3. Estimation of limits of detection (LODs) of sugar beet-specific PCR methods

Successively diluted solutions of genome DNA extracted from leaves of sugar beet plant (cultivar Skane) were prepared and were examined by PCR amplifications with primer pair 1 (A) and primer pair 2 (B). PCR products were electrophoresed on 3\% agarose gels. Lanes $1-5$, the amplifications of sugar beet DNA extractions containing 500 copies, 100 copies, 20 copies, 10 copies, and 5 copies per reaction, respectively; Lane 6, negative control without template; P, positive control (same as sugar beet genomic DNA samples for 20 copies); M, 100 bp ladder size standard. DNA concentrations were calculated from UV absorption using a $C$-value a $26 \mathrm{pg} / 2 C$. Each reaction was performed in three replications with independent extractions.

pairs would be suitable as taxon-specific controls in future detection methods for GM sugar beets.

Qualitative PCR analysis of residual DNA in beet sugar

As the template in PCR for in-process samples and beet sugar products, the permissible maximum volume of the undiluted DNA extracts was added to the PCR reactions, and the amount of DNA used for each reaction ranged from $40 \mathrm{ng}$ to $239 \mathrm{ng}$ as calculated from the 


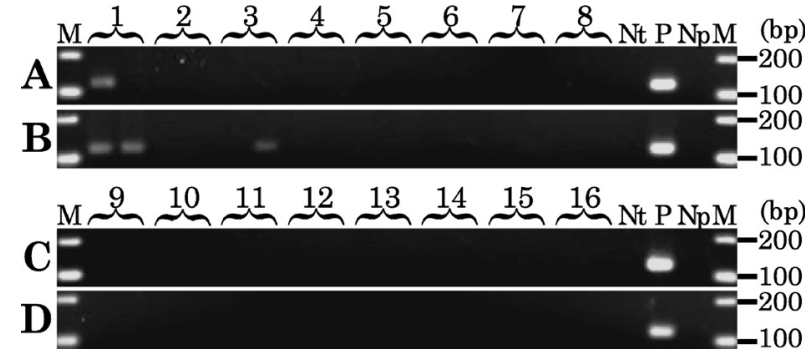

Fig. 4. Analysis of residual DNA in in-process products and commercialized beet sugar product

PCR products amplified with the primer pair 1 $(\mathrm{A}, \mathrm{C})$ and the primer pair 2 (B, D) were electrophoresed on $3 \%$ agarose gels. Lanes 1-8, detection of sugar beet DNA from the in-process products indicated in Fig. 1; lanes 9-16, detection of sugar beet DNA from commercial beet sugar products, namely brown sugar (1), brown sugar (2), syrup-type product with added oligosaccharide, granulated sugar (1), white superior sugar, brown sugar (3), bleached brown sugar, and granulated sugar (2), respectively. P, detection of sugar beet DNA extracted from seedlings as a positive control; Nt, negative control without template; $\mathrm{Np}$, negative control without primers; M, 100 bp ladder size standard. Each reaction was performed in two replications with independent extractions.

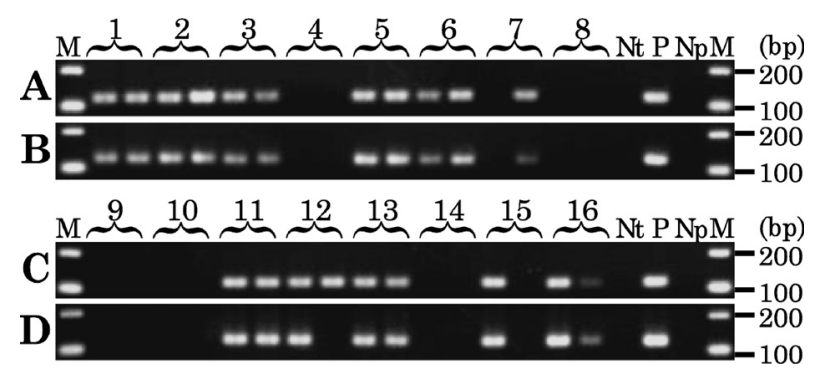

Fig. 5. Inhibition assay

Sugar beet DNA (260 pg) extracted from leaves of sugar beet plant (cv. Skane) was spiked in a reaction mixture containing $16.875 \mu \mathrm{L}$ of extracts from samples. Amplification was performed with the primer pair $1(\mathrm{~A}, \mathrm{C})$ and the primer pair $2(\mathrm{~B}, \mathrm{D})$, and products were analyzed by electrophoresed on 3\% agarose gels after the thermal cycling. Lanes $1-8$, detection of sugar beet DNA from in-process products as indicated in Fig. 1; lanes 9-16, detection of sugar beet DNA from commercial beet sugar products, namely brown sugar (1), brown sugar (2), syrup-type product with added oligosaccharide, granulated sugar (1), white superior sugar, brown sugar (3), bleached brown sugar, and granulated sugar (2), respectively. $\mathrm{P}$, detection of sugar beet DNA extracted from leaves as a positive control; Nt, negative control without template; Np, negative control without primers; M, 100 bp ladder size standard. Each reaction was performed in two replications with independent extractions.
UV absorption. In the case of in-process sugars, amplification was observed in the earlier stages of processing, such as thin juice and the thick juice, but no amplification was observed in the case of samples from later stages (Figs. 4A, B). In addition, for inhibition assay of the extracts, we evaluated amplification from samples spiked with 20 copies of sugar beet genome DNA extracted from leaves. The inhibition assays were performed in duplicate for each extract. The results indicated that amplifications were strongly inhibited (2 out of 2 ) in in-process syrup samples (\#4) and brown sugars (\#8, \#9, $\# 10$, and \#14) and partially inhibited in in-process syrup samples (\#7) and some commercial sugars (\#12 and \#15) (Fig. 5). Although some samples may contain PCRinhibitory substances, the results on the in-process samples suggested that the sugar beet DNA was degraded in the early stage of the sugar processing. Thus, it is unlikely residues of DNA are present at measurable levels in commercial beet sugars.

\section{Conclusion}

Our results suggested that it is difficult to extract DNA for PCR analyses from processed sugar beets. Although we rely on imported sugar materials, import of raw sugar beets into Japan is forbidden for phytosanitary reasons*2. GM sugar beets generally come into the Japanese market as processed sugars or partially purified sugars. In Japan, the mandatory GM labeling is not required for processed foods that do not contain a sufficient amount and/or quality of marker DNAs or proteins, e.g. cooking oil and soy sauce*3. Based on the result of this investigation, the Japanese government has decided that the mandatory GM labeling is not applicable the sugar products. Moreover, we found taxon-specific primer pairs for sugar beet plants, and clarified that these primers were appropriate to use as taxon-specific controls for GMO analysis by PCR. The results will be useful for future development of detection methods of GM sugar beets.

\section{Acknowledgements}

This study was supported in part by a grant from the Ministry of Agriculture, Forestry and Fisheries of Japan for the Research Project, "Assurance of Safe Use of Genetically Modified Organisms", and also by a grant from the Ministry of Health, Labor and Welfare of Japan. We would like to thank the Japan Beet Sugar Association for kindly providing information about beet sugar processes and specimens of in-process products.

\footnotetext{
*2 http://www.pps.go.jp / english / law / list 1-(20080412-). html

*3 Notification No. 517 (Mar. 31, 2000), Labeling standard for genetically modified foods. Ministry of Agriculture, Forestry and Fisheries of Japan.
} 


\section{References}

1) James, C. Global status of commercialized biotech/GM crops 2007. ISAAA Briefs, 37, ISAAA, Ithaca, NY (2007).

2) Hino, A. Safety assessment and public concerns for genetically modified food products: the Japanese experience. Toxicol. Pathol., 30, 126-128 (2002).

3) Yoshimura, T., Kuribara, H., Kodama, T., Yamata, S., Futo, S., Watanabe, S., Aoki, N., Iizuka, T., Akiyama, H., Maitani, T., Naito, S., Hino, A. Comparative studies of the quantification of genetically modified organisms in food from maize and soy using trial producing. J. Agric. Food Chem., 53, 2060-2069 (2005).

4) Möhring, S., Salaminiand, F., Schneider, K. Multiplexed, linkage group-specific SNP marker sets for rapid genetic mapping and fingerprinting of sugar beet (Beta vulgaris L.). Molecular Breeding, 14, 475-488 (2004).

5) Arumuganathan, K., Earle, E. D. Nuclear DNA content of some important plant species. Plant Mol. Biol. Rep., 9(3), 208-218 (1991). 